\title{
Reflexos do SIMPLEs nacional no emprego e na formalização do mercado de trabalho no Brasil
}

\section{Reflexes of SIMPLES nacional on formal employment and labor market in Brazil}

\author{
Nelson Leitấo-Paes
}

\begin{abstract}
Resumo
As microempresas e as pequenas empresas (MPE) brasileiras possuem alta representatividade na economia e apresentam uma série de singularidades na tributação. Com o simples Nacional, o Brasil concedeu benefícios fiscais e simplificações administrativas para as MPE. Este artigo investigou os efeitos do SIMPLES Nacional sobre a formalização das firmas e o emprego. Verificou-se que o número de empresas optantes pelo regime cresceu a um ritmo bem superior ao das demais empresas. As empresas optantes também foram capazes de gerar relativamente mais empregos do que as náo-optantes, com uma taxa de crescimento do emprego superior para o primeiro grupo.
\end{abstract}

Palavras-chave: SIMPLES Nacional, formalização, emprego, salários.

\begin{abstract}
Micro and small enterprises (SMEs) have high representation in the Brazilian economy, presenting a number of singularities about taxation. With SIMPLES Nacional, Brazil granted a series of tax and administrative simplifications for SMEs. This article investigates the effects of the introduction of SIMPLES Nacional on the formalization of firms and employment. It was found that the number of companies opting for the regime grew at a rate above that of non-chooser companies. SMEs inside SIMPLES Nacional were also able to generate relatively more jobs than non-choosers, with a growth rate of employment higher for the first group.
\end{abstract}

Keywords: SIMPLES Nacional, formalization, employment, wages.

* Universidade Federal de Pernambuco. Correo-e: nlpaes@gmail.com 


\section{Introduçáo}

As microempresas e as pequenas empresas (MPE) possuem uma importância significativa para a economia na maioria dos países ocidentais. Segundo a OCDE (2009), em seus países membros MPE representam 94\% das empresas industriais e mais de $95 \%$ das empresas de serviços. ${ }^{1}$ Elas têm um peso fundamental no emprego, respondendo por quase $60 \%$ do emprego industrial dentro da OCDE, bem como $67 \%$ do total de empregos no setor de serviços em 2005.

A realidade brasileira não é diferente. Segundo pesquisa do DIEESE ${ }^{3}$ (2011), com base em dados da rais, ${ }^{4}$ no final de 2010, a participação no emprego das microempresas e empresas de pequeno porte era de $52 \%$ do total. Por outro lado, representavam $99 \%$ do total de empresas no país.

Trata-se, portanto, de um grupo expressivo e que apresenta uma série de singularidades no que diz respeito à tributação. Devido ao fato de serem pequenas, estas empresas podem incorrer em custos econômicos superiores ao das maiores empresas. Nesse sentido, muitos países têm buscado criar mecanismos específicos que permitam as MPE ter igualdade de condiçôes em relação às grandes no que tange as suas obrigaçôes tributárias. Assim, simplificações de declarações, eliminação de obrigações acessórias e mesmo redução da carga tributária tem sido utilizada pelas Administraçôes Tributárias no enfrentamento da questão.

O Brasil concedeu uma série de benefícios fiscais e simplificaçôes administrativas para as microempresas e pequenas empresas desde a criação do simples ${ }^{5}$ pela Lei $n^{\circ} 9.317 / 96$. Houve redução da carga tributária, simplificação da escrituração fiscal, pagamento em um único documento de vários tributos federais e a possibilidade de se incluir mediante convênio, também os tributos estaduais e municipais. $\mathrm{O}$ passo seguinte, na mesma lógica de reduzir custos para as pequenas empresas, foi o lançamento do simples Nacional, Lei Complementar no 123/2006, que ampliou os benefícios do SIMPLES ao incluir explicitamente os mais importantes tributos estaduais, o ICMS, ${ }^{6} \mathrm{E}^{\mathrm{MUNICIPAIS}}$, O ISS. ${ }^{7}$

\footnotetext{
${ }^{1}$ Considerando apenas as microempresas e pequenas empresas.

${ }^{2}$ Em relação ao emprego os números incluem também as empresas médias.

${ }^{3}$ Departamento Intersindical de Estatística e Estudos Socioeconômicos. Instituição vinculada ao Sindicato de trabalhadores de São Paulo.

${ }^{4}$ Relação Anual de Informaçōes Sociais. A rais é uma pesquisa coletada pelo Ministério do Trabalho e Emprego.

${ }^{5}$ Sistema Integrado de Pagamento de Impostos e Contribuiçôes das Microempresas e das Empresas de Pequeno Porte.

${ }^{6}$ Imposto sobre Circulaçáo de Mercadorias e Serviços - Trata-se do principal tributo brasileiro, arrecadado sobre a base consumo e administrado pelos Estados.

${ }^{7}$ Imposto sobre Serviços. É o mais importante imposto municipal.
} 
Este artigo trata de investigar os efeitos da criação do SIMPLEs Nacional sobre a formalização das firmas e sobre a criação de empregos. $\mathrm{O}$ objetivo é buscar evidências sobre o impacto do sIMPLEs Nacional, comparando inclusive o seu desempenho com aquele apresentado pelo regime anterior, o SIMPLES.

Trata-se de matéria relevante para os formuladores de política econômica já que os custos envolvidos em programas de redução da carga tributária para as pequenas empresas são bastante elevados no Brasil. A Secretaria da Receita Federal do Brasil, em seu último demonstrativo de gastos tributários (RFB, 2OI 2), estima a renúncia fiscal dentro do SIMPLES Nacional em quase R\$ 22 bilhóes em 2009.

Após esta breve introdução, o artigo apresenta, de forma resumida, a evolução da legislação brasileira em relação ao tratamento tributário concedido as microempresas e as empresas de pequeno porte, a partir da criação do SIMPLES em 1996 até a adoção do SIMPLEs Nacional em 2007.

$\mathrm{Na}$ seçấo seguinte apresenta-se uma breve revisão da literatura, com um panorama das principais contribuiçóes a pesquisa do impacto dos regimes simplificados sobre as pequenas empresas, especificamente no que diz respeito à formalização e a criação de vagas.

$\mathrm{Na}$ seção 3 inicia-se uma análise dos efeitos do Simples Nacional sobre a economia brasileira, enfocando questôes como formalização das empresas, criação de empregos e impactos sobre os salários. Várias bases de dados são analisadas na busca de evidências. De maneira geral, perceberam-se impactos positivos sobre a formalização e o emprego, porém com custos elevados em razão da expressiva renúncia fiscal. Ainda, verificou-se que o regime simplificado ajudou na sustentação da economia brasileira durante a crise de 2008-2010 com forte criação ou formalização de empresas optantes, enquanto o número de não-optantes diminuía no período.

Por fim, a última seção resume as principais conclusões do trabalho e apresenta os comentários finais.

\section{Breve resumo da Legislação Tributária Brasileira aplicada as Microempresas e as Empresas de Pequeno Porte}

Criado em 5 de dezembro de 1996 pela Lei Federal no. 9.317/96, o Sistema Integrado de Pagamento de Impostos e Contribuiçóes das Microempresas e das Empresas de Pequeno Porte (simples) consubstanciou no mundo tributário brasileiro o tratamento mais favorecido as pequenas 
empresas. O SIMPLEs englobava uma série de tributos federais, ${ }^{8}$ além da contribuição previdenciária patronal, que poderiam ser pagos com apenas um documento de arrecadação e cujo valor era calculado como um percentual do faturamento da empresa. O sistema previa uma substancial redução na carga tributária das pequenas empresas, além de facilidades administrativas como a entrega de uma declaração anual simplificada e a dispensa de escrita contábil formal.

A opção pelo simples era restrita a empresas com faturamento anual inferior a $\mathrm{R}$ \$ 1,2 milhão e que se enquadrassem nas atividades econômicas aceitas pelo regime. Posteriormente, em 2006 este limite foi aumentado para $\mathrm{R} \$ 2,4$ milhóes.

Dentro do SIMPLEs, havia a previsão legal de que os principais tributos de Estados e Municípios poderiam ser incluídos no regime mediante convênio. Na prática, porém, não houve interesse dos demais entes federativos e o regime continuou a ser essencialmente voltado para os tributos federais.

A aprovação da Lei Complementar n. 123 de 14 de dezembro de 2006 atendeu ao antigo pedido das pequenas empresas e modificou o SIMPLES para a criação do SIMPLES Nacional. Neste novo regime, o sistema deixa de ser apenas federal e passa a ser administrado por Municípios, Estados e União. A administração, arrecadação, cobrança e fiscalização são compartilhadas entre os entes da federação. Em consequência, foram incorporados ao regime o ICMS, maior imposto brasileiro em termos de arrecadação, e o Iss, o que representou nova rodada de redução de carga tributária e de simplificaçóes administrativas para as pequenas empresas brasileiras. A partir de janeiro de 2012, o limite para opção pelo SIMPLES Nacional foi novamente elevado para R \$ 3,6 milhóes.

\section{Revisáo de literatura}

A importância das MPE na economia é inquestionável, dado o enorme peso deste segmento no número de empresas e na geração de postos de trabalho. Naturalmente, os governos tendem a olhar para as pequenas e micro empresas com o cuidado e a atenção que merecem.

Especificamente, países de várias partes do mundo procuram fazer com que os respectivos sistemas tributários não afetem adversamente, em termos comparativos, as MPE em relação às maiores empresas.

\footnotetext{
${ }^{8}$ Estavam incluídos o Imposto de Renda da Pessoa Jurídica (IRPJ), a Contribuição para os Programas de Integração Social e de Formação do Patrimônio do Servidor Público (PIS/PASEP), a Contribuição Social sobre o Lucro Líquido (CSLL), a Contribuição para Financiamento da Seguridade Social (Cofins) e o Imposto sobre Produtos Industrializados.
} 
$\mathrm{Na}$ literatura econômica brasileira já existem alguns artigos que abordem o regime tributário diferenciado para as MPE. Todos os artigos encontrados tratam apenas do sIMPLES, exceto o de Castro (2010) que inclui também o SIMPLES Nacional.

A maioria dos trabalhos brasileiros aponta para efeitos positivos da introdução de regimes tributários diferenciados para as pequenas empresas sobre a formalização e a criação de novas firmas além de impactar positivamente na formalização e geração de empregos.

Tal resultado não chega a ser surpreendente já que a literatura internacional tem colocado os pequenos negócios como a principal fonte de geração de empregos para diversos países (Neumark et al. (2008), Audretsch (2002), Davidsson et al. (1998), Baldwin e Picot (1995).

Um dos primeiros trabalhos a tratar do tema foi o de Lemgruber e Rodrigues (2000). Este artigo, com base em dados das Declaraçóes de Imposto de Renda das empresas, constatou que a introdução do SIMPLES em 1997 não levou ao aumento da formalização das firmas entre 1996 e 1997, mas por outro lado, verificam que houve aumento substancial do emprego para as firmas com até nove empregados.

Cechin e Fernandes (2000) acompanharam um grupo de 1'218,219 empresas entre janeiro de 1996 e janeiro de 1998. Todas elas se enquadravam na opção pelo SIMPLES. Verificaram que houve um expressivo aumento do emprego, que quase dobrou no período para o grupo analisado.

Monteiro (2004) aponta que o principal beneficiário da introdução do SIMPLES foi o setor de comércio com aumento de formalização estimado da ordem de 19\%, seguido pelo setor de serviços, com $8 \%$. De fato, os dados mostram que mais de $80 \%$ das empresas optantes pelo simples Nacional pertencem a estes dois setores (IBGE, 2005).

Delgado et al. (2007) usando dados da GFIP" entre 2000 e 2005 observam que o número de empresas optantes cresceu mais de $40 \%$ no período e que houve expressivo crescimento do emprego, mas que ocorreu de forma mais dispersa e não apenas no grupo até nove empregados. Os autores ainda encontram um aumento no número de empregados por estabelecimento optante, acompanhada, porém, de pequena redução no salário médio.

Monteiro e Assunção (2006) estudaram o efeito do SIMPLES sobre a formalização das firmas. Usando dados da Pesquisa da Economia Informal e Urbana (Ecinf) do IBGE em 1997, os autores verificaram que, confirmando estudos anteriores, a maior formalização ocorreu no setor de co-

\footnotetext{
${ }^{9}$ Guia de Recolhimento do fgts e Informaçōes à Previdência Social, documento apresentado pelas empresas com os recolhimentos previdenciários de seus funcionários.
} 
mércio varejista. Para os demais setores não foi encontrada evidência robusta de que o regime simplificado tenha induzido a maior formalização.

Fajnzylber et al. (2009) também avaliam o efeito do sIMPLES sobre a formalização das pequenas empresas brasileiras. Os dados para o estudo foram obtidos das Pesquisas Ecinf de 1997 e 2003. Encontram que o SIMPLES teve efeitos importantes na formalização das pequenas empresas, e que tais firmas geram mais receitas e lucros, contratam mais trabalhadores e são mais intensivas em capital. Segundo os autores, é o baixo custo de contratação que leva a adoção de técnicas produtivas que envolvem maior permanência e maior salário para a força de trabalho.

Courseuil e Moura (2009) avaliaram a contribuiçáo do sIMPLES para a geração de empregos no setor industrial entre 1997 e 1999. Com dados da Pesquisa Industrial Anual (PIA) do IBge, verificaram que de fato as empresas aproveitaram as vantagens do regime simplificado para contratar mais empregados.

Paes e Almeida (2009) estudam o efeito do SIMPLES entre 1997 e 2005. Como toda a literatura sobre o tema, encontram efeitos positivos na criação de empregos, mas por outro lado não percebem mudanças na informalidade. Segundo os autores, o sIMPLES não foi efetivo na formalização das empresas brasileiras. Por outro lado, em posição crítica ao regime simplificado, afirmam que o custo da renúncia fiscal do SIMPLES é elevado e comparaçóes realizadas entre empresas optantes e não-optantes pelo regime sugerem que o segundo grupo apresentou melhor desempenho.

Castro (2010) inova na literatura brasileira ao trazer os impactos iniciais do SIMPLEs Nacional, mas restringe o seu estudo somente a uma unidade da federação, o Distrito Federal. A análise contemplou apenas os seis primeiros meses iniciais do novo regime tributário. De acordo com o trabalho, o sIMPLEs Nacional trouxe impactos positivos tanto para o emprego quanto para a remuneraçáo dos trabalhadores das micro e pequenas empresas no Distrito Federal.

O presente artigo segue na mesma linha dos anteriores com resultados similares. Também aqui, se verifica os efeitos positivos do SIMPLES e do SIMPLEs Nacional sobre a formalização das firmas, criação de empregos e melhores salários. A grande contribuição do artigo é sugerir que os efeitos já documentados pela literatura no SIMPLES, permaneceram e mesmo se aprofundaram com a introdução do SIMPLEs Nacional. E isto ocorreu não apenas em uma unidade da federação, como em Castro (2010), mas para todo o país. 


\section{Experiência América Latina}

A grande maioria dos países da América Latina possui em seu código tributário mecanismos destinados especialmente para favorecer as pequenas empresas. Em geral tais regimes implicam não só em simplificações nas obrigaçôes tributárias, mas também em tributação mais favorecida.

Tais sistemas se justificam por conta dos elevados custos de cumprimento das obrigaçôes principais e acessórias que acabam sendo desproporcionalmente maiores para as pequenas empresas.

Os regimes simplificados tipicamente reduzem substancialmente os custos contábeis e de entrega de declaraçóes e periodicidade de pagamentos, como também oferecem uma maneira SIMPLEs de apurar os tributos devidos, adotando-se uma alíquota padronizada em relação às receitas das empresas optantes. São métodos presumidos de determinação do imposto (Corbacho et al., 2013).

O objetivo básico é oferecer uma possibilidade de formalização dos negócios e dos empregos a ele associados. A tabela 1 apresenta alguns regimes na América Latina.

O Brasil, primeiramente com o sIMPLES e atualmente com o SIMPLES Nacional, adota uma estratégia para as pequenas empresas que se enquadra bem na experiência latino-americana. Ambos os programas apresentam um sistema similar aos da tabela 1 , com pagamentos únicos mensais englobando vários tributos, como o Imposto de Renda e tributos sobre o consumo, além das contribuiçóes previdenciárias.

O sistema brasileiro, porém se destaca pela sua generosidade. O limite no sIMPLES Nacional anual é de R \$ 3,6 milhóes, o que equivale a US\$ 1,5 milhăo, muito superior aos limites vigentes nos demais países da América Latina. Ademais contempla uma gama de tributos que só se compara ao monotributo argentino.

\section{Efeitos do SIMPLES Nacional}

Nesta seção procura-se encontrar evidências do efeito do SIMPLEs Nacional sobre o comportamento das pequenas empresas brasileiras. Nesta tarefa, vamos buscar informaçóes em diferentes fontes de dados, como a GFPI, a RAIS, pesquisas do IBGE e da RFB.

O simples Nacional estabelecido pela Lei Complementar $n^{\circ} .123$ de 14 de dezembro de 2006 prevê um regime tributário diferenciado para as microempresas e empresas de pequeno porte a partir de 1 julho de 2007 e sucedeu, com maior abrangência, o antigo sIMPLES, pois incorporou de maneira sistemática o ICMs dos Estados e o Iss dos municípios. 


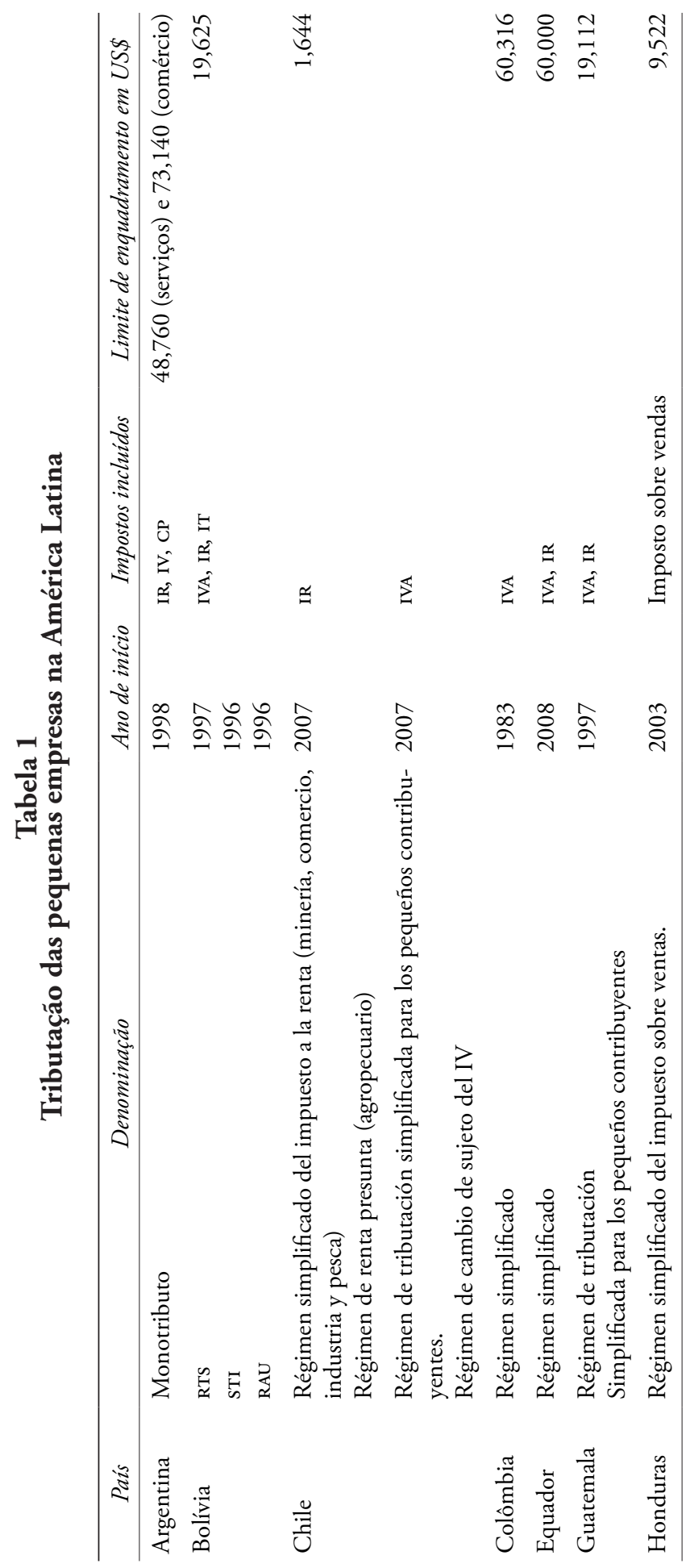




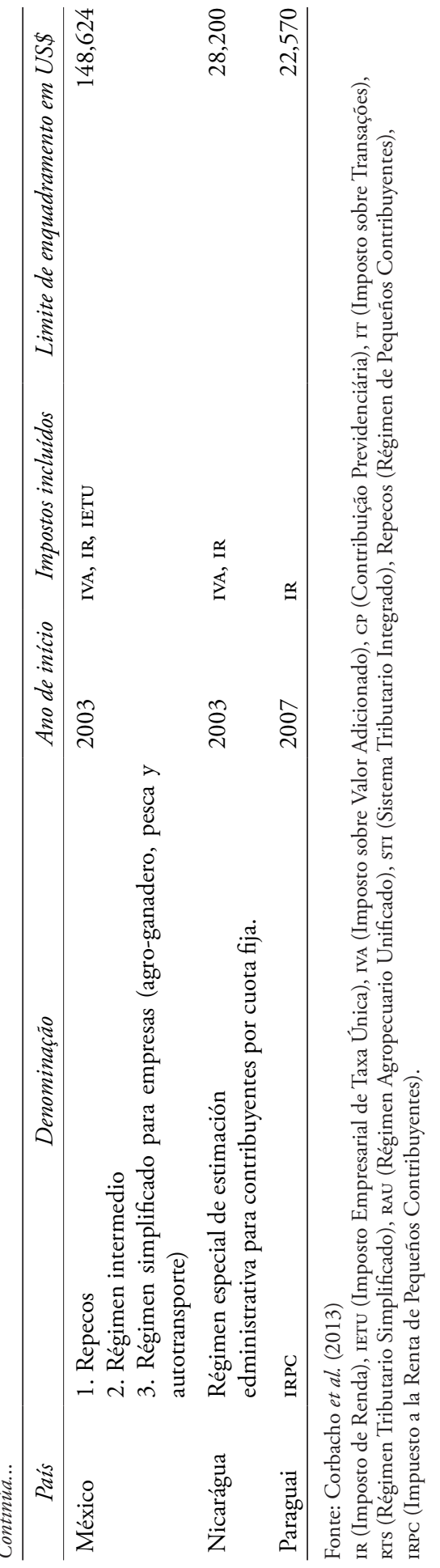




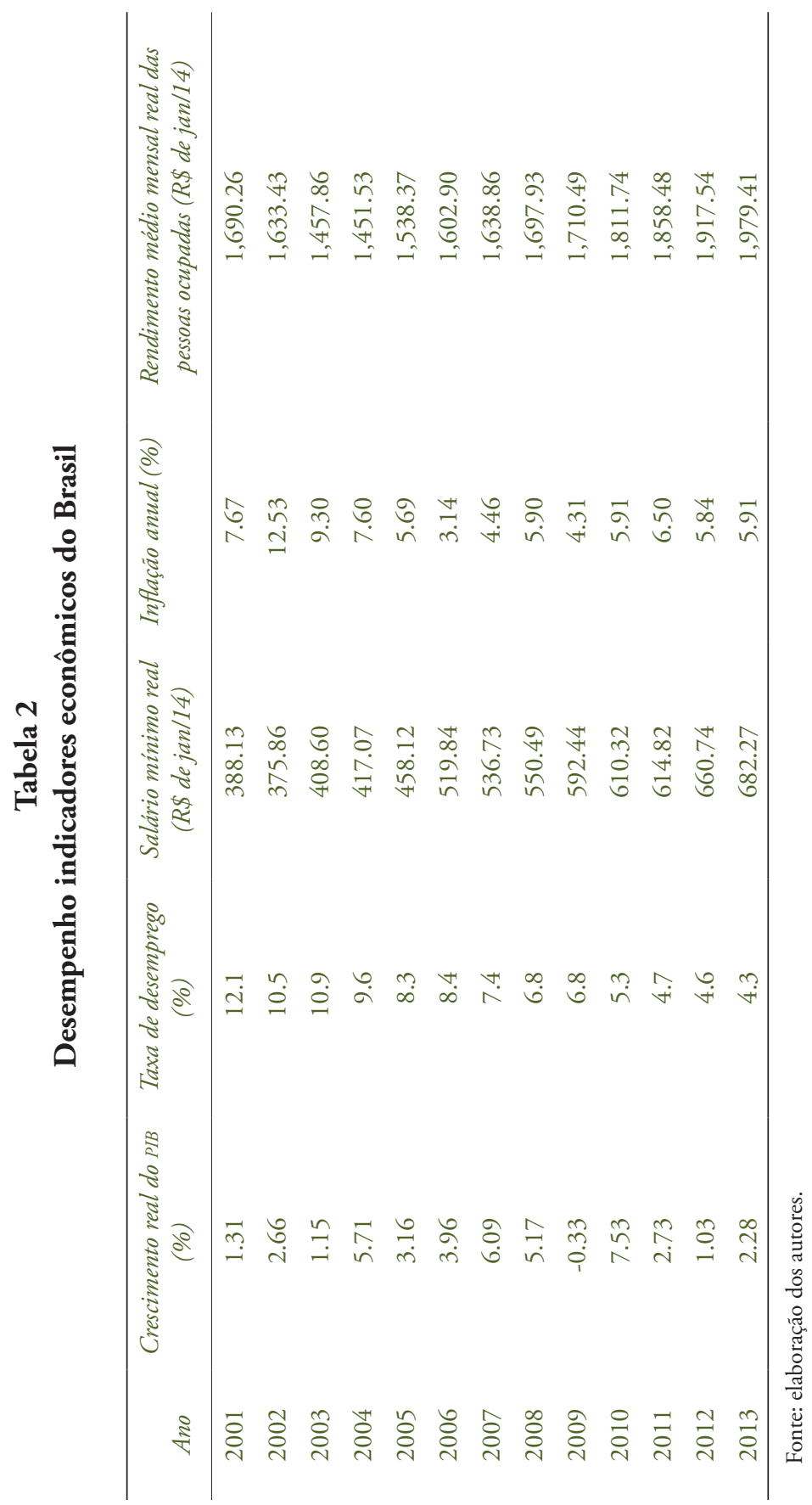


Ao se restringir o objeto da análise ao SIMPLEs Nacional, restringe-se também o espaço temporal disponível de dados. Há informações apenas no período de agosto de 2007 a dezembro de 2012. Trata-se de um conjunto de informaçóes relativamente limitado. Mas, ainda assim, os dados coletados nos permitem fazer inferências acerca dos efeitos do SIMPLES Nacional, principalmente sobre a formalização e o mercado de trabalho.

Há de se lembrar, também, da grave crise internacional que assolou a economia mundial, cujos efeitos mais agudos aconteceram entre 2008 e 2009. Os dados nos permitem dizer que o simples Nacional foi um dos fatores que permitiram que a economia brasileira não fosse tão severamente atingida quanto outras economias pelo mundo.

\subsection{Panorama da economia brasileira}

Para melhor compreensão dos resultados sobre o mercado de trabalho que serão apresentados nas seçôes seguintes, é interessante trazer um breve apanhado dos principais indicadores da economia brasileira entre 2001 e 2013, objeto do presente estudo.

A tabela 2 mostra a evolução de variáveis importantes para a compreensão da dinâmica econômica no Brasil no passado recente.

O quadro econômico brasileiro em 2001 não era muito favorável. A economia vinha crescendo lentamente, a taxa de desemprego e a inflaçáo eram elevadas e o salário mínimo relativamente baixo (em torno de US\$ 160). Por outro lado, o país realizou reformas importantes como a do sistema financeiro, a do regime previdenciário, a responsabilidade fiscal, as privatizaçôes e instituiu o regime de metas de inflação.

A chegada do presidente Lula ao governo em 2003 não implicou em grandes mudanças macroeconômicas. A estabilidade fiscal, o câmbio flutuante e as metas de inflação permaneceram como um sólido tripé para o governo. As mudanças que ocorreram tinham um caráter mais social. O governo brasileiro passou a promover aumentos deliberados no poder de compra do salário mínimo e consolidou e ampliou os programas sociais no Brasil.

O país apresentou um crescimento moderado quando se observa todo o período, embora tenha conseguido atingir números expressivos entre 2004 e 2010 quando a taxa média de crescimento foi de 4,5\% ao ano. Os principais motivos apontados para este desempenho foram o aumento dos preços das commodities que beneficiou fortemente o Brasil, a política de estímulo ao crédito do governo federal e os expressivos aumentos do salário mínimo e de programas de assistência social, que geraram grande impulso na demanda brasileira. A economia reduziu o seu crescimento a partir de 2011, o que tem sido atribuído a problemas do lado 
da oferta, notadamente na baixa taxa de investimento do país que perdura já há algum tempo.

Dois fatos se destacam quando se analisa a tabela 1 . O primeiro é a forte redução do desemprego no país. A taxa caiu de em quase $70 \%$ passando de 12,1\% em 2001 para 4,3\% em 2013, a menor desde que se começou a coletar esta informação. E o desemprego tem cedido, mesmo com a forte desaceleração do crescimento ocorrida a partir de 2011. Acredita-se que os principais motivos para a expressiva queda no desemprego estejam ligados a fatores demográficos como a diminuição da taxa de crescimento da população economicamente ativa, que tem afetado a oferta de mão de obra.

Um segundo ponto importante é o expressivo aumento do salário mínimo, fruto de ação deliberada do governo para reduzir a pobreza e estimular a economia. Entre 2003 e 2013, o salário mínimo no Brasil aumentou quase $67 \%$ em termos reais e hoje vale algo em torno de US\$ 300. Chama a atenção que este forte aumento do salário mínimo foi acompanhado de substancial redução no desemprego. Por fim, vale ressaltar que o rendimento médio do trabalhador não acompanhou o desempenho do salário mínimo, mas apresentou um robusto resultado de aumento de 35\% em termos reais entre 2003 e 2013.

Em resumo, a economia brasileira vinha apresentando forte crescimento desde 2003, mas sofreu uma desaceleração a partir de 2011, embora isto não tenha sido sentido no mercado de trabalho que continua vigoroso.

\subsection{Efeito sobre a formalização das empresas}

Para se buscar evidências do efeito do sIMPLEs Nacional sobre a formalização das empresas, a base de dados utilizada foram os dados da GFIP, coletados mensalmente para o período de janeiro de 2001 a dezembro de 2010 (último dado disponível). Os números, agregados por ano, encontram-se na tabela 3 .

O período entre janeiro de 2001 e junho de 2007 estava sob vigência do SIMPLES e percebe-se um vigoroso crescimento no número de estabelecimentos no regime, muito acima do crescimento dos estabelecimentos náo-optantes. O resultado acima é consistente com a pesquisa de Delgado et al. (2007) que verificou forte crescimento do número de optantes para o período de 2000 a 2005, tanto com dados da GFIP quanto da RAIs. Estes autores concluem não ser possível rejeitar a hipótese de que houve significativa elevação do número de estabelecimentos formais em decorrência do simples. Já Paes e Almeida (2009), bem como Lemgruber e 


\section{Tabela 3}

Número de estabelecimentos GFIP

\begin{tabular}{llrrr}
\hline \multicolumn{1}{c}{ Mês } & \multicolumn{1}{c}{ Ano } & \multicolumn{1}{c}{ Optante } & Não-optante & \multicolumn{1}{c}{ Total } \\
\hline Janeiro & 2001 & $1,319,394$ & $1,495,495$ & $2,814,889$ \\
Dezembro & 2002 & $1,437,173$ & $1,397,648$ & $2,834,821$ \\
Dezembro & 2003 & $1,462,660$ & $1,259,566$ & $2,722,226$ \\
Dezembro & 2004 & $1,467,416$ & $1,234,078$ & $2,701,494$ \\
Dezembro & 2005 & $1,826,240$ & $1,476,884$ & $3,303,124$ \\
Dezembro & 2006 & $1,846,369$ & $1,378,700$ & $3,225,069$ \\
Junho & 2007 & $2,029,898$ & $1,528,535$ & $3,558,433$ \\
Variação anual & & $6.85 \%$ & $0.34 \%$ & $3.67 \%$ \\
Julho & 2007 & $1,931,035$ & $1,627,521$ & $3,558,556$ \\
Dezembro & 2008 & $2,093,595$ & $1,781,342$ & $3,874,937$ \\
Dezembro & 2009 & $2,239,921$ & $1,810,092$ & $4,050,013$ \\
Dezembro & 2010 & $2,272,576$ & $1,737,604$ & $4,010,180$ \\
Dezembro & 2011 & $2,463,099$ & $1,854,589$ & $4,317,688$ \\
Dezembro & 2012 & $2,516,632$ & $1,825,459$ & $4,342,091$ \\
Variaçáo anual & & $3.75 \%$ & $0.49 \%$ & $2.30 \%$ \\
\hline
\end{tabular}

Fonte: elaboração dos autores.

Rodrigues (2000) não encontram evidências de maior formalização por conta do SIMPLES.

Quando se considera o período abrangido pelo simples Nacional, julho de 2007 a dezembro de 2012 se verifica uma desaceleraçáo no crescimento do número de estabelecimentos no regime favorecido, com manutenção na taxa de crescimento dos não-optantes em patamar bem inferior a taxa dos optantes. Novas empresas continuam entrando no SIMPLES Nacional, mas a um ritmo menor do que anteriormente no SIMPLES. Ainda assim, há evidência de que quando uma empresa é criada ou decide se formalizar, na sua maioria das vezes irá optar pelo regime simplificado.

É preciso fazer um destaque para o comportamento de optantes e não-optantes no período da crise mundial 2008-2010. Entre 2008 e 2010 foram criadas cerca de 200 mil empresas optantes, enquanto que o número de não-optantes foi reduzido em cerca de 50 mil empresas. Há, portanto, indício de que o sIMPLEs Nacional, apesar da forte crise, conseguiu manter algum ritmo de crescimento, colaborando para sustentar a economia em um momento difícil. 


\subsection{Efeito sobre o emprego}

A inclusão da contribuição previdenciária no sIMPLES, e depois mantida no simples Nacional, demonstra que o principal intuito dos regimes simplificados era e continua a ser a criação de empregos. Paes e Almeida (2009) e Delgado et al. (2007) examinaram o efeito do SIMPLEs sobre o emprego e concluíram que de fato, o regime simplificado teve efeitos positivos na criação de empregos no Brasil durante a sua vigência.

O que se quer investigar agora é se o sIMPLEs Nacional também foi capaz de manter o perfil pró-emprego do seu antecessor. Para esta análise temos dados da GFIP e da RAIs. Iniciamos com as informaçóes da GFIP, condensadas na tabela 4:

\section{Tabela 4 \\ Quantidade de vínculos GFIP}

\begin{tabular}{llrrr}
\hline \multicolumn{1}{c}{ Mês } & \multicolumn{1}{c}{ Ano } & \multicolumn{1}{c}{ Optante } & Näo-Optante & \multicolumn{1}{c}{ Total } \\
\hline Janeiro & 2001 & $4,251,621$ & $17,122,317$ & $21,373,938$ \\
Dezembro & 2002 & $5,158,001$ & $17,701,597$ & $22,859,598$ \\
Dezembro & 2003 & $5,182,063$ & $17,734,732$ & $22,916,795$ \\
Dezembro & 2004 & $5,473,598$ & $18,199,198$ & $23,672,796$ \\
Dezembro & 2005 & $6,350,235$ & $19,464,639$ & $25,814,874$ \\
Dezembro & 2006 & $7,149,945$ & $20,800,607$ & $27,950,552$ \\
Junho & 2007 & $7,455,462$ & $22,486,624$ & $29,942,086$ \\
Variação anual & & $9.03 \%$ & $4.28 \%$ & $5.32 \%$ \\
Julho & 2007 & $7,040,663$ & $23,182,607$ & $30,223,270$ \\
Dezembro & 2008 & $7,801,843$ & $25,517,818$ & $33,319,661$ \\
Dezembro & 2009 & $8,382,468$ & $26,471,213$ & $34,853,681$ \\
Dezembro & 2010 & $9,311,042$ & $28,207,623$ & $37,518,665$ \\
Dezembro & 2011 & $9,949,169$ & $30,460,075$ & $40,409,244$ \\
Dezembro & 2012 & $10,581,393$ & $30,904,571$ & $41,485,964$ \\
Variação anual & & $6.28 \%$ & $3.40 \%$ & $4.04 \%$ \\
\hline
\end{tabular}

Fonte: elaboração dos autores.

Percebe-se que o SIMPLES Nacional, apesar de alguma desaceleração em relaçấo ao seu antecessor, manteve um ritmo bom de crescimento de empregos, e ainda muito superior ao ritmo de crescimento do emprego das empresas de fora do regime. Segundo dados acima, as empresas optantes do SIMPLes Nacional contrataram mais de 3,5 milhóes de trabalhadores desde a sua criação. Este comportamento é similar ao que se percebe na taxa de desemprego. Conforme a tabela 1, o desemprego no 
país teve uma queda mais expressiva entre 2001 e 2007, do que nos anos posteriores. Há também que se considerar que reduçóes expressivas no desemprego, que se reflete em maiores contrataçóes, tornam-se mais difíceis à medida que a taxa de desemprego reduz o seu patamar.

Note que durante o período da crise (2008-2010), a taxa de crescimento do emprego dentro do simples Nacional foi de $6,1 \%$ ao ano enquanto para as empresas fora do regime foi de apenas 3.4\%. Assim, durante a crise, o emprego cresceu quase o dobro dentro das empresas do SIMPLES Nacional quando comparado as demais empresas.

Os dados da RAIs, diferentemente da GFIP, são anuais, de forma que estabelecemos o ano de 2007 como o início do SIMPLEs Nacional. As informações na RAIsnão estão estruturadas entre optantes e não-optantes do regime simplificado e sim por porte da empresa considerando o número de empregados. Seguindo metodologia de Delgado et al. (2007), foram considerados como optantes, as empresas com até 9 empregados e como não-optantes, aquelas com 10 ou mais. Tais considerações são importantes, pois mostram que os dados da RAIs para o nosso estudo são menos precisos do que os obtidos da GFIP. Ainda assim, podem trazer subsídios para análise do mercado de trabalho.

Os resultados são distintos aos obtidos com as informaçóes da GFIP e constam na tabela 5:

\section{Tabela 5}

\section{Quantidade de vínculos RAIS}

\begin{tabular}{lccr}
\hline \multicolumn{1}{c}{ Ano } & Até9 empregados & 10 ou mais empregados & \multicolumn{1}{c}{ Total } \\
\hline 2001 & $4,836,441$ & $22,353,173$ & $27,189,614$ \\
2002 & $5,096,215$ & $23,587,698$ & $28,683,913$ \\
2003 & $5,271,377$ & $24,273,550$ & $29,544,927$ \\
2004 & $5,526,238$ & $25,881,338$ & $31,407,576$ \\
2005 & $5,770,781$ & $27,467,836$ & $33,238,617$ \\
2006 & $5,991,722$ & $29,163,527$ & $35,155,249$ \\
Variação anual & $4.38 \%$ & $5.46 \%$ & $5.27 \%$ \\
2007 & $6,199,634$ & $31,407,796$ & $37,607,430$ \\
2008 & $6,513,728$ & $32,927,838$ & $39,441,566$ \\
2009 & $6,815,942$ & $34,391,604$ & $41,207,546$ \\
2010 & $7,216,283$ & $36,852,072$ & $44,068,355$ \\
2011 & $7,599,140$ & $38,711,491$ & $46,310,631$ \\
2012 & $7,901,993$ & $39,556,719$ & $47,458,712$ \\
Variação anual & $4.97 \%$ & $4.72 \%$ & $4.76 \%$ \\
\hline
\end{tabular}

Fonte: elaboração dos autores. 
Os dados da RAIS apontam para uma taxa de crescimento do emprego para as pequenas empresas bem inferior ao obtido com os dados da GFIP, mas ainda muito expressivo superior a $5 \%$ ao ano. Os dados da RAIs também apontam que o simples Nacional acelerou levemente a taxa de crescimento do emprego em relação a taxa anterior obtida pelo SIMPLES. Observe que a taxa de crescimento do emprego das empresas acima de 10 empregados teve uma pequena redução na vigência do SIMPLES Nacional.

Ao contrário da GFIP que aponta para maiores taxas de contrataçóes nas pequenas empresas, o quadro que emerge da RAIs é mais homogêneo, com pequenas empresas e demais empresas apresentando taxas de contratação similares. As taxas de contratação no total são bem similares, em torno de $4 \%$ a $5 \%$, e conjectura-se que esta pequena diferença de comportamento entre pequenas e demais empresas nas duas pesquisas esteja relacionada ao fato de que algumas empresas pequenas estão impedidas de optarem pelo simples Nacional por conta da atividade que desenvolvem.

Ambas as pesquisas mostram que o ritmo de contrataçóes no país continua forte e, de certo modo generalizado na economia, e ajudam a entender as baixas taxas de desemprego apresentadas na tabela 1 .

Os dados da GFIP também permitem analisar a quantidade de empregados por estabelecimento, bastando utilizar as informaçóes das tabelas 2 e 3 .

\section{Tabela 6}

\section{Quantidade de vínculos por estabelecimento GFIP}

\begin{tabular}{llrrr}
\hline \multicolumn{1}{c}{ Mês } & \multicolumn{1}{c}{ Ano } & Optante & Não-Optante & \multicolumn{1}{c}{ Total } \\
\hline Janeiro & 2001 & 3.22 & 11.45 & 7.59 \\
Dezembro & 2002 & 3.59 & 12.67 & 8.06 \\
Dezembro & 2003 & 3.54 & 14.08 & 8.42 \\
Dezembro & 2004 & 3.73 & 14.75 & 8.76 \\
Dezembro & 2005 & 3.48 & 13.18 & 7.82 \\
Dezembro & 2006 & 3.87 & 15.09 & 8.67 \\
Junho & 2007 & 3.67 & 14.71 & 8.41 \\
Variaçáo anual & & $2.03 \%$ & $3.93 \%$ & $1.59 \%$ \\
Julho & 2007 & 3.65 & 14.24 & 8.49 \\
Dezembro & 2008 & 3.73 & 14.33 & 8.6 \\
Dezembro & 2009 & 3.74 & 14.62 & 8.61 \\
Dezembro & 2010 & 4.10 & 16.23 & 9.36 \\
Dezembro & 2011 & 4.04 & 16.42 & 9.36 \\
Dezembro & 2012 & 4.20 & 16.93 & 9.55 \\
Variaçáo anual & & $2.89 \%$ & $3.51 \%$ & $2.38 \%$ \\
\hline
\end{tabular}

Fonte: elaboração dos autores. 
Destaca-se a aceleração do crescimento das empresas optantes durante o período de vigência do simples Nacional em relação ao período do SIMPLES. Para as demais empresas, ocorreu justamente o inverso, com desaceleração no número de empregados por estabelecimento. $\mathrm{O}$ bom resultado alcançado pelo simpLEs Nacional permite a suposição de que as empresas continuaram a ser criadas durante o novo regime, mas as empresas existentes cresceram e contrataram mais trabalhadores, de forma que o crescimento do emprego foi maior do que o do número de empresas.

Os resultados são compatíveis com a evolução do mercado de trabalho observada na tabela 1 . As empresas, tanto as pequenas quanto as demais, tem aumentado o número médio de trabalhadores. Pela tabela anterior, uma pequena empresa contratou em média um empregado a mais entre 2001 e 2012. Já as demais empresas contrataram cerca de cinco empregados a mais neste mesmo período. Como houve também aumento no número de empresas, ver tabela 2 , especialmente das pequenas, que duplicaram neste período, o efeito sobre a diminuição do desemprego foi realmente importante.

Em resumo, o que os dados apresentados permitem inferir é que o SIMPLES Nacional, mantendo o padrão verificado com o sIMPLES, continuou a gerar mais empregos em relação a empresas de fora do regime. A taxa de crescimento do número de empresas optantes do simples Nacional foi bastante superior a dos não-optantes. Os dados da RAIs também apontam que a taxa de crescimento do emprego durante a vigência do SIMPLES Nacional acelerou em relaçáo à taxa obtida pelo SIMPLES para as empresas até 9 empregados. Ainda, verificou-se que a relação do número de empregados por estabelecimento cresceu mais rapidamente na vigência do SIMPLEs Nacional do que com o SIMPLES, mas ainda inferior a taxa encontrada para os não-optantes. Sinal de que além da criação de empresas, o SIMPLES Nacional auxiliou no crescimento das pequenas firmas.

\subsection{Efeito sobre o salário}

Em relação ao salário, tanto a RAIS quanto a GFIP tem dados disponíveis. Começando pela massa salarial, verificou-se forte aumento durante toda a década passada, seja na vigência do simples ou do SIMPLEs Nacional. Os dados foram anualizados e deflacionados pelo IPCA. ${ }^{10}$ Considerou-se o período entre 2001 e 2006, como aquele abarcado pelo simples, e o período entre 2007 e 2012 pelo simples Nacional.

${ }^{10}$ Índice Nacional de Preços ao Consumidor Amplo, representa a estimativa oficial de inflação no Brasil. 


\section{Tabela 7}

Massa Salarial (deflacionada pelo IPCA) GFIP (R\$ Milhóes)

\begin{tabular}{lrrr}
\hline \multicolumn{1}{c}{ Ano } & \multicolumn{1}{c}{ Optante } & Não-optante & \multicolumn{1}{c}{ Total } \\
\hline 2001 & $37,665,371$ & 339.932 .691 & $377,598.062$ \\
2002 & $41,883,822$ & $322,379,943$ & $364,263,765$ \\
2003 & $45,077,059$ & $329,461,588$ & $374,538,647$ \\
2004 & $48,941,196$ & $352,134,734$ & $401,075,930$ \\
2005 & $56,079,957$ & $379,517,718$ & $435,597,675$ \\
2006 & $66,043,156$ & $398,988,251$ & $465,031,407$ \\
Variação anual & $11.89 \%$ & $3.26 \%$ & $4.25 \%$ \\
2007 & $71,234,908$ & $451,282,323$ & $522,517,231$ \\
2008 & $76,829,797$ & $505,968,470$ & $582,798,266$ \\
2009 & $85,720,338$ & $539,086,179$ & $624,806,516$ \\
2010 & $98,305,723$ & $588,047,747$ & $686,353,469$ \\
2011 & $117,347,243$ & $696,252,728$ & $813,599,972$ \\
2012 & $135,636,139$ & $754,125,468$ & $889,761,606$ \\
Variação anual & $13.75 \%$ & $10.82 \%$ & $11.23 \%$ \\
\hline
\end{tabular}

Fonte: elaboração dos autores.

O forte crescimento real da massa salarial se manteve durante toda a década, independente do regime simplificado em vigor. Tal resultado é especialmente notável levando em conta a grave crise mundial entre 2008 e 2010. Em todos os períodos a massa salarial das empresas optantes se comportou de maneira muito favorável, com crescimento sempre acima de $10 \%$ ao ano.

Quando comparamos a tabela acima com a tabela 3 com dados da evolução do emprego, fica claro que o que explica metade do crescimento da massa salarial foram as contrataçóes. O emprego cresceu fortemente entre as empresas optantes e tal resultado se refletiu sobre a massa salarial.

Outro ponto que merece destaque foi a forte aceleração da massa salarial entre as empresas náo-optantes. Em verdade, a taxa de crescimento da massa salarial para este grupo de empresas triplicou na última metade da década passada. Embora importante, o peso da criação de novas vagas explica muito menos este crescimento acelerado do que no caso das empresas optantes. Observando os dados da tabela 3 verifica-se que houve de fato um aumento na taxa de crescimento do emprego entre os náooptantes, mas longe do grande incremento da massa salarial.

Em relação ao salário médio, Delgado et al. (2007), analisando o período entre 2000 e 2005, verificou que o salário pago pelas empresas optantes permaneceu estagnado neste período. Já para as empresas não- 
optantes houve um crescimento real dos salários médios pagos. Segundo os autores, em 2000 optantes e náo-optantes pagavam um salário médio muito próximo, de $\mathrm{R} \$ 501,58$ e $\mathrm{R} \$ 504,99$, respectivamente. Porém em 2005 o desempenho díspare dos dois grupos fez com que o salário médio dos optantes ficasse em $\mathrm{R} \$ 504,50$, enquanto que o dos não-optantes saltasse para $\mathrm{R} \$ 593,10$, um incremento de quase 20 por cento.

Delgado et al. (2007) conjecturam que tal desempenho ruim dos optantes poderia estar ligado ao fato de que boa parte do setor de serviços estava impedido legalmente de optar pelo simples. Porém, como bem apontado por Paes e Almeida (2009), esta explicação não encontra amparo nos dados das Contas Nacionais que apontam para maior crescimento dos salários no setor industrial entre 2001 e 2005.

Com os dados da GFIP e da RAIs foi possível obter o salário médio para o período de 2001 a 2010. E os números obtidos são bastante distintos da pesquisa de Delgado et al. (2007). A tabela 8a presenta os números da GFIP:

\section{Tabela 8}

Salário médio (deflacionado pelo IPCA) GFIP (em R\$)

\begin{tabular}{lccc}
\hline \multicolumn{1}{c}{ Ano } & Optante & Não-optante & Total \\
\hline 2001 & 738.26 & 1654.43 & 1472.19 \\
2002 & 676.68 & 1517.66 & 1327.90 \\
2003 & 724.89 & 1548.10 & 1361.95 \\
2004 & 745.11 & 1612.41 & 1411.87 \\
2005 & 735.93 & 1624.82 & 1406.16 \\
2006 & 769.74 & 1598.46 & 1386.47 \\
Variação anual & $0.84 \%$ & $-0.69 \%$ & $-1.19 \%$ \\
2007 & 843.14 & 1622.20 & 1440.71 \\
2008 & 820.64 & 1652.34 & 1457.59 \\
2009 & 852.18 & 1697.08 & 1493.88 \\
2010 & 879.83 & 1737.26 & 1524.47 \\
2011 & 982.89 & 1904.82 & 1677.83 \\
2012 & 1068.20 & 2033.48 & 1787.27 \\
Variação anual & $4.85 \%$ & $4.62 \%$ & $4.41 \%$ \\
\hline
\end{tabular}

Fonte: elaboração dos autores.

Uma primeira observação é que a introdução do SIMPLEs Nacional parece ter levado a uma forte aceleraçáo da taxa de crescimento do salário médio. Outra observação é que durante toda a década passada os salários cresceram mais rapidamente no grupo das empresas optantes do que no grupo das empresas não-optantes. 
Percebe-se também que os rendimentos dos trabalhadores, seja das pequenas empresas, seja das demais empresas, permaneceu estagnado, ou até mesmo diminuiu em termos reais entre 2001 e 2006. É um resultado que já havia aparecido no dado macroeconômico da tabela 1 , que mostra a queda do rendimento médio real das pessoas ocupadas neste período. E isto ocorreu apesar do aumento do salário mínimo do período, também demonstrado na tabela 1. É preciso lembrar que neste período a taxa de desemprego decresceu fortemente, mas partiu de um patamar elevado em 2001. As firmas neste período, portanto, contrataram mais trabalhadores, porém sem elevar os salários.

A partir de 2007, o salário mínimo cresce a taxa média real anual de $4,2 \%$, o rendimento médio das pessoas ocupadas também aumenta em $3,2 \%$ ao ano. Estes números são muito próximos ao que mostra a pesquisa da GFIP, com aumento acima de $4 \%$ no rendimento dos trabalhadores. A diferença em relação ao período anterior está no desemprego. Observe que em 2007 a taxa de desemprego sofre uma queda substancial de um ponto percentual e vem se reduzindo substancialmente desde então. Ao contrário de 2001 a 2006, o mercado de trabalho torna-se mais apertado e isso se reflete nos aumentos salariais generalizados e que continuam a ocorrer.

Porém, os salários dos optantes são ainda bastante inferiores aos pagos pelos náo-optantes. Trata-se de um resultado natural, já que os salários tendem a ser menores nas pequenas empresas, por conta da sua necessidade de mão-de-obra menos qualificada e diversificada, em relação às grandes empresas.

Ainda assim, a relação entre o salário médio pago pelas optantes em relação as não-optantes, aumentou de 44,6\% em 2001 para 52,5\% em 2012. Este aumento reflete não só as sucessivas elevaçóes do salário mínimo, mas também o crescimento das pequenas empresas, evidência já coletada na seção 3.2 .

Merece destaque a inversão do comportamento dos salários no grupo não-optante. No período de 2001 a 2006 verificou-se uma queda dos salários neste grupo, mas que voltou a crescer a partir de 2007 a 2012. Como já dito, o bom momento em relação ao emprego vivido pelo país no final da década anterior é o principal fator por trás desta reversão do comportamento.

Por fim, os resultados encontrados até aqui estão em contradição com os resultados obtidos por Delgado et al. (2007). Estes autores encontraram uma estagnação no salário médio dos optantes com pequeno crescimento no salário médio dos não-optantes. Resultado oposto foi verificado no presente estudo, estagnação nos não-optantes e crescimento do salário entre os optantes. Um dos fatores que podem ajudar a explicar é a diferença 
entre os períodos analisados. Para o mesmo período de análise, ou seja, a vigência do SIMPLES, os resultados são relativamente similares e apontam para a estagnação dos salários.

A RAIs também apresenta informaçôes sobre salários. Novamente, é preciso lembrar que, ao contrário da GFIP, a RAIS não separa as empresas entre optantes e não-optantes. Seguindo Delgado et al. (2007), considerou-se como pequena empresa, aquela com até 9 empregados.

\section{Tabela 9}

\section{Salário médio (deflacionado pelo IPCA) RAIS (em R\$)}

\begin{tabular}{lrrr}
\hline \multicolumn{1}{c}{ Ano } & Até 9 empregados & 10 ou mais empregados & \multicolumn{1}{c}{ Total } \\
\hline 2001 & 775.83 & $1,664.31$ & $1,506.57$ \\
2002 & 729.83 & $1,390.09$ & $1,399.73$ \\
2003 & 743.99 & $1,534.13$ & $1,393.15$ \\
2004 & 749.12 & $1,551.52$ & $1,410.34$ \\
2005 & 759.50 & $1,567.47$ & $1,427.20$ \\
2006 & 798.21 & $1,657.16$ & $1,510.77$ \\
Variação anual & $0.57 \%$ & $-0.09 \%$ & $0,06 \%$ \\
2007 & 851.23 & $1,745.29$ & $1,595.02$ \\
2008 & 875.75 & $1,807.55$ & $1,651.24$ \\
2009 & 916.88 & $1,854.86$ & $1,691.35$ \\
2010 & 941.16 & $1,900.89$ & $1,742.00$ \\
2011 & 1028.69 & $2,068.20$ & $1,896.73$ \\
2012 & 1025.07 & $2,010.83$ & $1,845.35$ \\
Variação anual & $3.79 \%$ & $2.87 \%$ & $2.96 \%$ \\
\hline
\end{tabular}

Fonte: elaboração dos autores.

O padrão apresentado pela RAIs é semelhante ao da GFIP. A taxa de crescimento na vigência do SIMPLES é que é mais baixa do que encontrado na GFIP. Mas, a forte aceleração do crescimento dos salários a partir de 2007 está presente a taxas similares. O mesmo padrão de expansão do emprego com estagnação dos salários observado na GFIP e nos dados da tabela 1 se mantém para o período 2001 a 2006. Já a partir de 2007, à medida que o desemprego cede, os ganhos salariais váo se avolumando.

Portanto, seja com dados da GFIP seja com informaçôes da RAIs, verificou-se forte aceleração dos salários na economia como um todo a partir de 2007, após um período de estagnação até 2005. É difícil argumentar que tal desempenho se deve a introdução do simples Nacional, uma vez que tal aceleração ocorreu tanto em relação às empresas optantes como entre as não-optantes, mas também em relação às empresas com até 9 
empregados e empresas com 10 ou mais empregados. $\mathrm{O}$ motivo basicamente é a baixa taxa de desemprego no país, que permitiu que os salários tivessem um bom crescimento de forma generalizada a partir de 2007.

\section{Conclusóes}

Este artigo procurou avaliar os efeitos da implantação do SIMPLES Nacional na economia brasileira. A análise se concentrou no período de 2001 a 2010 e foi possível estabelecer comparaçôes não só entre grupo de empresas optantes e não-optantes pelo regime favorecido, como também comparar os números do SIMPLes Nacional com os do SIMPLES.

Verificou-se que o simples Nacional é a principal porta de entrada das empresas brasileiras tanto na criação quanto na formalização. As empresas optantes cresceram a um ritmo bem superior ao das empresas não-optantes durante toda a década anterior, sendo que no momento da grave crise internacional, houve crescimento do número de optantes com decréscimo no número de não-optantes.

As empresas optantes pelo simples Nacional também foram capazes de gerar relativamente mais empregos do que as não-optantes, com uma taxa de crescimento do emprego superior para o primeiro grupo. Analisando-se os dados do número de empregados por estabelecimento, verificou-se que as empresas optantes também aumentaram mais rapidamente esta relaçáo do que as não-optantes, revertendo a tendência contrária que se observou durante a vigência do simples. Trata-se de forte indicativo de que não apenas novas empresas preferem entrar no mercado formal via SIMPLEs Nacional, mas que as que já são optantes estão crescendo dentro do regime. Sintomático também é o forte aumento da massa salarial e do salário médio, ambos com crescimento mais elevado para as empresas dentro do SIMPLES Nacional do que as de fora do regime.

As evidências coletadas sugerem que o simples Nacional teve um efeito importante sobre a economia nos últimos anos. Porém, trata-se de sistema que tem um custo muito elevado para a sociedade brasileira. Recomenda-se, portanto, que as Administraçóes Tributárias envolvidas sejam vigilantes e cuidadosas no trato do regime simplificado evitando simulaçóes e permitindo que apenas pequenas empresas permaneçam no regime.

\section{Referências bibliográficas}

Audretsch, David (2002), "The Dynamic Role of Small Firms: Evidence from the us", Small Business Economics, 18, Springer, Amsterdam, pp. 13-40. 
Baldwin, John e Garnett Picot (1995), "Employment Generation by Small Producers in the Canadian manufacturing sector", Small Business Economics, 7, Springer, Amsterdam, pp. 317-331.

Castro, André Lima (2010), "Uma análise do impacto do simples Nacional no DF”, Dissertação de Mestrado, Universidade de Brasília, Brasília.

Cechin, José e Alexandre Zioli Fernandes (2000), Boletim Informativo GFIP: avaliação dos dados, Ministério da Previdência e Assistência Social, Brasília.

Corbacho, Ana, Vicente Fretes e Eduardo Lora (2013), Recaudar no basta: los impuestos como instrumento de desarrollo, Banco Interamericano de Desenvolvimento, Washington.

Courseuil, Carlos Henrique e Rodrigo Leandro de Moura (2009), "O SIMPLEs federal e a geração de empregos na indústria”, XXXVII Encontro Nacional da Associação Nacional dos Centros de PósGraduação em Economia (ANPEC), dezembro 2009, Foz do Iguaçu, Paraná.

Davidsson, Per, Leif Lindmark and Christer Olofsson (1998), "The Extent of Overestimation of Small Firm Job Creation: An Empirical Examination of the 'Regression Bias', Small Business Economics, 10, Springer, Amsterdam, pp. 87-100.

Delgado, Guilherme, Ana Carolina Querino, André Campos, Fábio Vaz, Leonardo Rangel e Matheus Stivali (2007), "Avaliação do sIMPLEs: implicaçôes à formalizaçáo previdenciária”, texto para Discussão 1.277, Instituto de Pesquisa Econômica Aplicada, Brasília.

DIEese (Departamento Intersindical de Estatística e Estudos Socioeconômicos) (2011), Anuário do trabalho da micro e pequena empresa, Serviço Brasileiro de Apoio às Micro e Pequenas Empresas, Brasília.

Fajnzylber, Pablo, William Frederick Maloney e Gabriel Montes-Rojas (2009), Does Formality Improve Micro-Firm Performance? Quasiexperimental evidence from the Brazilian SIMPLES Program, discussion paper num. 4531, IZA, Bonn. 
IBGe (Instituto Brasileiro de Geografia e Estatística) (2005), Economia Informal Urbana 2003, Instituto Brasileiro de Geografia e Estatística, Rio de Janeiro.

Lemgruber, Andrea and Jefferson Rodrigues (2000), Tratamento tributário da micro e pequena empresa no Brasil, Secretaria da Receita Federal do Brasil, Brasília.

Monteiro, Joana (2004), "Microempresas no Brasil: informalidade e contratos de trabalho", dissertação de mestrado, Pontifícia Universidade Católica do Rio de Janeiro, Rio de Janeiro.

Monteiro, Joana e Juliano Assunção (2006), "Outgoing the Shadows: Estimating the Impact of Bureaucracy Simplification and Tax cut on Formality and Investment", mimeo, Pontifícia Universidade Católica, Rio de Janeiro, <http://epge.fgv.br/files/2066.pdf>, 26 novembro de 2012.

Neumark, David, Brandon Wall e Junfu Zhang (2008), "Do Small Businesses Create More Jobs? New Evidence for the United States from the National Establishment Time Series", Social Science Research Network, working paper num. w13818, California.

OCDE (Organização para Cooperação e Desenvolvimento Econômico) (2009), Taxation of Small and Medium Enterprises - Key Issues and Policy Considerations, OCDE, Paris.

Paes, Nelson e Aloísio Almeida (2009), "Tributação da Pequena Empresa e Avaliação do simples", Caderno de Finanças Públicas, 9, Escola de Administração Fazendária, Brasília, pp. 5-55.

RFB (Secretaria da Receita Federal do Brasil) (2012), "Demonstrativo dos Gastos Tributários - Estimativas Bases Efetivas 2009”, RFB, Brasília.

Recibido: 13 de enero de 2013. Reenviado: 21 de agosto de 2013. Aceptado: 17 de marzo de 2014 
Nelson Leitão Paes. Brasileiro. É doutor em economia pela Universidade de Brasília. Atualmente é Professor do Programa de Pós-Graduação em Economia da Universidade Federal de Pernambuco (Ufpe), assessor do secretário de Política Econômica do Ministério da Fazenda do Brasil e pesquisador do Conselho Nacional de Desenvolvimento Científico e Tecnológico $(\mathrm{CNPq})$. Sua linha de pesquisa está relacionada à tributação e seus efeitos sobre a economia. Entre as suas últimas publicaçôes destacam-se "O hiato tributário do imposto sobre produtos industrializados evidências setoriais", Revista Brasileira de Economia de Empresas, 11 (2), Universidade Católica de Brasília, Brasília, pp. 39-51 (2012); "O parcelamento tributário e seus efeitos sobre o comportamento dos contribuintes", Revista EconomiA, 13 (2), Associação Nacional dos Centros de Pós-Graduação em Economia, Brasília, pp. 345-363 (2012); "Impactos de longo prazo de reformas fiscais sobre a economia brasileira", Revista Brasileira de Economia, 66 (2), Fundação Getúlio Vargas, Rio de Janeiro, pp. 247-269 (2012); em co-autoria e "Reforma Tributária - os efeitos macroeconômicos e setoriais da PEC 233/2008”, Estudos Econômicos, 41 (2), Fundação Instituto de Pesquisas Econômicas, Sao Paulo, pp. 487-512 (2011). 